\title{
Del Tribunal de Garantías Constitucionales al Tribunal Constitucional peruano. Análisis jurídico-político comparativo.
}

Juan Morales Godo

«El constitucionalismo es probablemente el mayor resultado conseguido por la civilización moderna y poco o nada del resto de esa civilización es concebible sin aquél. Bajo él, por primera vez en la historia humana, se ha conseguido para el hombre corriente un cierto grado de libertad y bienestar".

Friedrich

1. Aspectos políticos que rodearon la Constitución de 1979

\subsection{Retorno a la democracia en el Perú y América Latina}

Las décadas de los años sesenta y setenta estuvieron marcadas, en América Latina, por la presencia y hegemonía de gobiernos militares. El militarismo cobró fuerza en muchos países latinoamericanos, ante el fracaso de los débiles e incipientes gobiernos elegidos por el voto popular en los años sesenta. Esta época no era mas que la repetición de una constante en la vida independiente de los países del sur de América ${ }^{1}$.

El Perú no fue ajeno a ello. En 1968, se instauró un gobierno militar que derrocó al entonces Presidente de la República, don Fernando Belaunde Terry. Bajo la dirección del General Juan Velasco Alvarado, el

1 En esas décadas se produjo una ola de golpes de Estado en América del Sur, encabezadas por militares. Argentina tuvo golpes militares en 1967 y 1974; Chile y Paraguay en 1973; Perú en 1968. 
Gobierno Revolucionario de las Fuerzas Armadas, tuvo dos etapas marcadas que concluyeron con la convocatoria a elecciones, primero para la conformación de una Asamblea Constituyente (1978), y luego para el Gobierno que asumiría la dirección del país (1980).

La primera etapa de este Gobierno militar, la dirigió el General Juan Velasco Alvarado, hasta el año 1975, quien fue derrocado por el General Francisco Morales Bermúdez, que estuvo en el poder hasta 1980, cuando fue elegido democráticamente Presidente Constitucional de la República, nuevamente, el arquitecto Fernando Belaunde Terry.

La primera etapa se caracterizó por las profundas transformaciones que se hicieron a la estructura de la sociedad peruana, que generó nuevas relaciones de poder. Esta etapa trajo consigo el «ocaso del poder oligárquico" ${ }^{2}$, instaurado en el Perú desde su independencia. Se intentó modelar una nueva sociedad.

Las primeras medidas adoptadas por el Gobierno militar fueron sorprendentes, tanto para el poder económico establecido, como para todos aquellos que pensaron que se trataba de un gobierno militar más, de otro golpe de Estado a los que nuestra vida republicana estuvo acostumbrada. Las medidas que se dictaron sucesivamente, fueron revelando que se trataba de un proyecto político inédito, de una clara tendencia socialista.

En los siete años de gobierno, bajo la dirección del General Juan Velasco Alvarado, se propició el avance de las fuerzas populares, aun cuando en una clara relación vertical con preponderancia del Estado. En esta etapa, el Estado generó una concentración de poder, por la gran participación en la economía nacional, que si bien lo distinguía muy claramente del Estado oligárquico anterior, se vio entrampado en sus propias reformas. Una de las últimas medidas radicales, fue la intervención de los medios de comunicación masiva por parte del Estado, con la finalidad de entregarlos a la sociedad organizada, llámese sindicatos, comunidades campesinas, colegios profesionales, universidades, etc. Sin embargo, el modelo no se cumplió a cabalidad, porque los directores de los medios de comunicación masiva fueron designados por el Gobierno y no por las organizaciones de base.

2 Henry Pease García. El ocaso del Poder Oligárquico. DESCO. Centro de Estudios y Promoción del Desarrollo, Lima, 1977. 
En 1975, el General Velasco, deteriorado en su salud, y ante la situación económica que comenzaba a presentar fisuras graves, fue derrocado por el General Francisco Morales Bermúdez, quien se encargó de ir desarmando las reformas efectuadas por el anterior gobernante.

A fines de la década del setenta y comienzos del ochenta, en América Latina, van tomando fuerza, las posiciones democráticas que claman porque se establezcan gobiernos basados en el voto popular y que se constituyan verdaderos Estados de derecho, luego de que las distintas experiencias militares fueron fracasando en su intento de resolver los problemas económicos del Estado ${ }^{3}$. En el Perú, esta tendencia toma fuerza, y es así como se convoca a elecciones en 1978, para una Asamblea Constituyente, encargada de la redacción de una nueva Constitución del Estado.

Los Constituyentes de 1978, imbuidos de una clara posición democrática, se abocan a la redacción de la Constitución, siendo firmes en lo que significa un Estado de derecho, fijando reglas de sometimiento a la Constitución de todos los poderes del Estado, con un claro sistema de control de la constitucionalidad de las leyes.

Con la experiencia del pasado tanto del Perú, como de América Latina, la Constitución de 1979, fue enfática en la defensa de los derechos fundamentales de la persona, del sometimiento de las Fuerzas Armadas a la Constitución, en la defensa misma de la Constitución, y en el control difuso y concentrado de la constitucionalidad de las leyes. Se trató de garantizar que la Constitución fuese una norma con permanencia en el tiempo.

Es necesario precisar que las constituciones no se convierten, por arte de magia, en la panacea para la solución de todos los males de una sociedad. De la desconfianza hacia el juzgador heredada de Europa, se pasó a la desconfianza del legislador, dada la hiperabundancia de leyes con resultados pocos eficaces. Entonces se recurre a la Constitución como el instrumento que puede propiciar el gran cambio en la sociedad, pero ésta será lírica si no tiene una traducción en la realidad. Se cree que todos los males se curarán con la Constitución, en ese sentido, si la sociedad tiene problemas hay que cambiar la Constitución. De

3 El retorno a la democracia eligiendo poderes constituyentes se produjo en el Perú en 1979, Brasil en 1988, Ecuador en 1978, Chile en 1980. 
esta forma, la Constitución se desvaloriza, peor aún, cuando se cambia para fomentar proyectos individuales o de grupo ${ }^{4}$.

\subsection{Razones por las que se optó por un Tribunal Constitucional}

En el caso peruano, las razones que tuvieron los constituyentes para optar por un Tribunal Constitucional, para el control de la constitucionalidad de las leyes, las podemos resumir en las siguientes:

A) La marcada dependencia del poder judicial hacia el poder político y económico y el escaso desarrollo jurisprudencial en materia de control de la constitucionalidad.

Esta es una apreciación histórica irrefutable, y uno de los principales argumentos por los cuales se optó por la creación de un Tribunal autónomo e independiente. En efecto, existía, como existe hasta la actualidad, desconfianza en el sistema judicial común, el que se presenta como ineficaz para la solución de los problemas que se ponen a su consideración. Esta ineficacia ha sido más notoria cuando se ha tratado de conflictos vinculados al tema de los Derechos Humanos, en los que generalmente, se encuentran de por medios actuaciones de los gobernantes de turno. Ha sido notoria la dependencia hacia el poder político $y$, no en menos ocasiones, hacia el poder económico, lo que ha producido una jurisprudencia, francamente, pobrísima. Los jueces, más preocupados en la conservación de su cargo, o en el próximo ascenso, fueron genuflexos ante el poder, con honrosas excepciones que la historia conservas.

4 Sobre estos aspectos leer el interesante ensayo de Domingo García Belaunde, "Procesos Constitucionales en América Latina», publicado en Desafíos Constitucionales Contemporáneos. Pucp, Lima, 1996.

5 Javier de Belaunde. "Problemas de la Justicia Ordinaria y Tribunal Constitucional». p. 128. El mismo autor relata, que el constituyente Javier Valle Riestra «trajo a colación en el debate constitucional aquel problema que se suscitó en la Corte Suprema cuando el Presidente Billinghurst fue derrocado y hubo un magistrado que para enervar el pronunciamiento de la Corte Suprema en torno al golpe de Estado preguntó: ¿Quién paga la quincena?. Esta situación (quizás históricamente algo caricaturesca) fue recordada en la Constituyente e indudablemente expresa cuán relevante fue el tema de la independencia del Poder Judicial y la tradición (salvo honrosísimas y muy destacables excepciones) de una cierta obsecuencia al poder, particularmente vinculada a la conflictividad constitucional». p. 128. 
B) De no considerarse un tribunal independiente del poder judicial y someter el control a este poder, ¿quién controlaría los actos inconstitucionales del poder judicial?

Este es un argumento que estuvo presente, inclusive, cuando se trató de la conformación del Tribunal Constitucional. Se cuestionaba que miembros del poder judicial formaran parte del Tribunal Constitucional, por considerar que no estarían propensos a examinar las resoluciones judiciales que transgredían la Constitución ${ }^{6}$.

C) La interpretación del derecho por parte del juez es distinta a la del magistrado constitucional. El primero generalmente es exegético, formalista y pegado a la ley. En cambio, la Constitución debe ser interpretada atendiendo a los principios y al desarrollo de las instituciones.

Nuestro punto de vista es que la interpretación en todos los campos del Derecho, no puede ser meramente exegética, con mayor razón en el campo constitucional. Sin embargo, en la justicia común, es cierto que los jueces tienen un apego a la norma en su sentido literal, limitando las interpretaciones. Muchas veces, dando prioridad a los aspectos formales, ritualizando el proceso, que lejos de ser un instrumento, un medio, se convierte en una finalidad en sí mismo. Javier De Belaunde ${ }^{7}$, señalaba que "el poder judicial expidiendo resoluciones, muchas veces no resuelve los conflictos que se presentan en la vida real. Busca «vías de evitamiento". El razonamiento judicial se vincula con frecuencia a un interés formalista de preservar la coherencia del ordenamiento jurídico como si fuera algo autónomo a la vida social. Así, el ciudadano común y corriente percibe que la interpretación judicial no prioriza debidamente el interés por solucionar el problema real. Este razonamiento no se orienta a resolver el conflicto. La prioridad, frecuentemente está puesta en cuestiones que terminan por eludir el problema de fondo. De este modo, la gente siente que su problema no fue procesado razonablemente».

Este es un grave defecto de la justicia común, provocado por el sistema mismo, en una clara desconfianza hacia el juzgador, creemos, en parte,

Referencias a las críticas formuladas en la Asamblea Constituyente también las hace Francisco Eguiguren, en El Tribunal de Garantías Constitucionales: las limitaciones del modelo y las decepciones de la realidad. p. 17.

6 Domingo García Belaunde. El Tribunal de Garantías Constitucionales en debate. pp. 136-137.

7 Javier de Belaunde. Op. cit. p. 128. 
por el desconocimiento de los principios que regulan el proceso. La novísima ciencia procesal no ha penetrado en las aulas universitarias, que todavía continúan en la etapa del procedimentalismo, creyendo que Derecho procesal es asunto de plazos, etapas, rigores formales, etc.

Creemos que el mal es interno, porque los jueces prefieren apegarse a la norma en su sentido literal, por temor a ser denunciados por prevaricato ${ }^{8}$, o ser quejados ante el órgano de control. Los encargados de ejercer el control, a su vez, son también pegados al sentido literal de la norma y aplican sanciones en base a dicho criterio.

En estos términos es difícil suponer que el poder judicial va a ejercer un verdadero control de la constitucionalidad de las leyes, toda vez que la interpretación constitucional se despliega más allá del mero sentido literal de la norma.

Es evidente que, en este tema, también cuenta la preparación profesional del juez que, en base a la producción y las estadísticas, deja mucho que desear.

D) El status del magistrado constitucional es diferente, ya que es elegido por un período determinado. No hace carrera ni está pegado al cargo.

Esta situación genera mayor independencia del magistrado constitucional. Actuará con mayor libertad, en conciencia que sus decisiones no comprometen su futuro en el Tribunal. La Constitución de 1993 ha incidido, indirectamente, en este tema, al eliminar la renovación por tercios de los miembros del Tribunal Constitucional.

Como se observa, la opción de un Tribunal Constitucional, se basó en un cuestionamiento del poder judicial ${ }^{9}$. A estas alturas, habría que preguntarse si estas observaciones, ¿no las podríamos hacer al mismo Tribunal Constitucional, con las honrosas excepciones de los tres magistrados cesados en sus cargos por el Congreso Nacional de la República?.

8 Recordemos que la Jueza Dra. Antonia Saquicuray, cuando prefirió aplicar la Constitución a la denominada ley de anmistía, en el caso de la masacre de los Barrios Altos, fue amenazada prácticamente por la Fiscal de la Nación, Dra. Blanca Nélida Colán, de ser denunciada por prevaricato.

9 Sobre el disgnóstico y realidad del Poder Judicial encontramos importantes conclusiones en los trabajos de Luis Pásara, en "Jueces, Justicia y Poder en el Perú", Lima 1982; también en Memorias de un Juez, Lima 1978; y recientemente en la publicación del Ministerio de Justicia «nuevas Perspectivas para la reforma integral de la Administración de Justicia en el Perún, Lima 1994. 


\section{Análisis jurídico-político comparativo del Tribunal de Garantías} constitucionales de 1979 y el Tribunal Constitucional de 1993.

\subsection{Autonomía e independencia}

La Constitución de 1979 crea el órgano encargado del control de la Constitucionalidad de las leyes, al que denomina Tribunal de Garantías Constitucionales, en demostración clara de la influencia del modelo español. Fue un órgano al que se le dotó de plena autonomía e independencia, aún cuando no se mencionan estas cualidades en la Carta suprema ${ }^{10}$.

En el pensamiento de los constituyentes estaba la creación de un ente independiente de los demás poderes del Estado, que procure el equilibrio indispensable en el ejercicio del poder que se les había conferido. Los poderes legislativo y ejecutivo son los que crean las normas en mayor proporción y trascendencia, por lo que tiene que ser otro organismo el que controle la coherencia de dichas normas con la Constitución. El organismo natural que debe encargarse de esta labor debería ser el poder judicial, en los mismos términos al sistema jurídico norteamericano. Sin embargo, ante la desconfianza en dicho poder del Estado, se opta por la creación de un ente jurisdiccional, autónomo e independiente de los demás poderes del Estado, siguiendo el modelo europeo (Austríaco).

El T.G.C. surge dentro de esta concepción y, por ende, se le dota de independencia para el ejercicio de sus funciones, tal como se reconoce expresamente en su Ley Orgánica, Ley $\mathrm{N}^{\circ} 23385$ Art. $1^{\circ}$. En efecto, el indicado numeral ratifica la condición de ser el órgano de control de la Constitución, remarcando que es independiente de los demás órganos constitucionales, encontrándose sometido sólo a la Constitución y a su ley orgánica. No está sujeto a órgano ni a poder alguno.

Es independiente porque no existe órgano superior a él, y porque sus miembros no están sujetos a mandato imperativo. No responden

10 Marcial Rubio y Enrique Bernales, Constitución y Sociedad Política p. 212. Los Constitucionalistas peruanos hacen hincapié en el hecho de que la Constitución no menciona que el Tribunal de Garantías Constitucionales es independiente, como si lo hace en reiteradas oportunidades respecto del Poder Judicial (Art. $233^{\circ}$ inc. 2 y $242^{\circ}$ inc. 1 ). 
Juan Morales Godo

por sus votos $u$ opiniones emitidas en el ejercicio de su cargo. De esta forma, quiso dotarse a los magistrados del T.G.C. de total independencia en el ejercicio de sus funciones, sin que exista vínculo alguno con los organismos que los han designado como tales.

Tampoco pueden ser denunciados ni detenidos durante su mandato, salvo los casos de flagrante delito y de acusación constitucional. Con ello se le brindaba la protección necesaria para el ejercicio libre e independiente de sus funciones.

Sin embargo, la independencia y autonomía no son cuestiones sólo de normas, sino de realidades. Lo cierto es que los miembros del T.G.C. no dieron muestras, salvo honrosas excepciones, de independencia respecto de los otros poderes del Estado; quizás por el sistema de nombramiento que se había diseñado (tres miembros eran elegidos por el Poder Legislativo, tres por el Poder Ejecutivo y tres por el Poder Judicial), como por la misma actitud personal de los magistrados, con lo que se reproducía lo que ocurría con el Poder Judicial.

La falta de independencia trajo consigo una pobrísima producción jurisprudencial, en lo que se refiere a las demandas de inconstitucionalidad de leyes, percibiéndose una disposición a no declarar la inconstitucionalidad de las leyes, para no perturbar la acción política de los partidos gobernantes de turno. Recordemos que tanto en el gobierno del Arquitecto Fernando Belaunde Terry (1980-1985), como en el gobierno de Alan García Pérez (1985-1990), se dio la circunstancia de que los partidos gobernantes (Partido Acción Popular y Apra, respectivamente), tenían mayoría parlamentaria, de tal suerte que tenían y ejercían el poder a través de los poderes legislativo y ejecutivo. Siendo así, los representantes al T.G.C. eran designados por ambos poderes, que lo ejercían los partidos gobernantes. En tal sentido, resultaban siendo mayoría en el Tribunal los nombrados por los partidos Acción Popular y Apra, respectivamente, a través del control que ejercían de los Poderes Legislativo y Ejecutivo (seis de nueve miembros).

La experiencia del T.G.C. nos demostró la relación que existe entre la falta de independencia de los magistrados con el sistema de nombramiento de los mismos, como ya lo había advertido Héctor Cornejo Chávez, en el debate de la Asamblea Constituyente de 1978-1979, cuando señalaba: "Si las facultades de este Tribunal han de ser de tal naturaleza que lo coloquen como un organismo censor, primero del Parlamento, pues tratará de declarar la eventual inconstitucionalidad 
de la ley, va a ser un organismo que estará vigilando nada menos que al Parlamento, o la inconstitucionalidad o ilegalidad de los decretos supremos u otras normas legales de menor jerarquía provenientes del Poder Ejecutivo, entonces estará controlando al Poder Ejecutivo. [...] Pero, entonces, yo le digo que no es conveniente que en ese organismo tengan demasiada presencia y por lo tanto gravitación los poderes pretendidamente controlados, el Parlamento o el Gobierno, porque sino no van a controlar nada. Sí, más bien, tuviesen gravitación personalidades o representantes de entidades muy respetables desde el punto de vista de su jerarquía y de su función y de que puedan permanecer al margen de todo lo político para poder controlar en forma imparcial y severa" ${ }^{11}$.

La Constitución de 1993, cambia de denominación, pero también opta por la creación de un Tribunal Constitucional, luego de que estuvo a punto de imponerse el criterio de crear una Sala especial dentro de la Corte Suprema de la República que se encargue del control de la constitucionalidad de las leyes. Esta vez, remarca en la propia Constitución (Art. $201^{\circ}$ ), que es el órgano de control de la Constitución, y es autónomo e independiente.

Esta autonomía e independencia de los demás órganos constitucionales es resaltada nuevamente por la Ley Orgánica del Tribunal Constitucional, Ley $\mathrm{N}^{\circ} 26435$, Art. $1^{\circ}$. Asimismo, el Art. $13^{\circ}$ del mismo cuerpo de leyes, señala que los magistrados no están sujetos a mandato imperativo, ni reciben instrucciones de ninguna autoridad, con lo que reafirman la independencia respecto del poder del Estado que los ha designado, como de cualquier otra autoridad. Gozan de inviolabilidad e inmunidad. No pueden ser detenidos ni procesados sin autorización del pleno del Tribunal, salvo flagrante delito. Antes era con acusación constitucional, ahora es con autorización del propio Tribunal en pleno.

Desde el punto de vista doctrinario esta posición es impecable, pero repetimos, la independencia no es cuestión de normas ni de declaraciones, sino de realidades. En la conformación del Tribunal Constitucional ha resultado sintomático el afán de contar con determinados miembros como magistrados, por parte del grupo mayoritario del Poder Legislativo, que es el mismo grupo que controlaba el Poder Ejecutivo.

11 Héctor Cornejo Chávez. Diario de los Debates. Comisión Principal de la Constitución de la Asamblea Constituyente 1978-1979. T. III. p. 357. 
El forcejeo en el nombramiento de los miembros del Tribunal Constitucional nos dio pautas para estar alertas respecto al desempeño de los magistrados.

\subsection{Composición y forma de designación}

Como ya se puede advertir, existe una relación gravitante entre la independencia del Tribunal Constitucional y la composición y forma de designación de los magistrados integrantes de dicho órgano. La experiencia del T.G.C. nos lo demostró, y los hechos ocurridos con motivo de la conformación del Tribunal Constitucional lo ratifica.

La Constitución de 1979, fijó en nueve, el número de miembros integrantes del T.G.C., tres designados por el Congreso, tres por el Poder Ejecutivo y tres por la Corte Suprema de Justicia. A dichos miembros se les extiende el título de Magistrados del Tribunal de Garantías Constitucionales (Art. $5^{\circ}$ Ley Orgánica del T.G.C., Ley N ${ }^{\circ}$ 23385).

El debate en la Comisión de Constitución de la Asamblea Constituyente de 1978-1979, fue amplio y ardoroso. El conocido y hoy retirado de la vida política, Dr. Héctor Cornejo Chávez, proponía la presencia de juristas que debían ser extraídos de las Facultades de Derecho de las Universidades, del ejercicio profesional, así como del poder judicial, toda vez que, como hemos hecho referencia líneas arriba, no concordaba con la idea de que en la designación participasen el poder legislativo y el ejecutivo. Proponía que tres fuesen designados por las Universidades, tres por los Colegios de Abogados, tres por el Poder Judicial, uno por el Poder Legislativo y uno por el Ejecutivo, lo que hacía un total de once miembros.

Finalmente, se impuso la propuesta del Dr. Mario Polar, que en concordancia con el Dr. Javier Valle Riestra, señalaba la conveniencia de que los miembros sean elegidos por el Congreso y el Poder Ejecutivo, ya que éstos eran elegidos por el pueblo, por lo que eran los llamados a representar indirectamente la voluntad popular, lo que otorga legitimidad a la designación ${ }^{12}$. El acuerdo final fue que los miembros

12 Mario Polar Ugarteche. Diario de Debates. Comisión Principal de la Constitución de la Asamblea Constituyente 1978-1979. Tomo III. p. 358. 
serían nueve, tres designaba el Congreso, tres el Poder Ejecutivo y tres la Corte Suprema de Justicia de la República.

Reconocidos juristas peruanos han señalado la ligazón que existió entre la falta de independencia de los miembros del Tribunal de Garantías Constitucionales y el sistema de nombramiento diseñado por la Constitución de 1979. Javier de Belaunde, señalaba el inconveniente que había ya previsto Cornejo Chávez en el debate en la Asamblea Constituyente, de la injerencia del poder político (Poder Legislativo y Ejecutivo) en la designación de los magistrados del T.G.C., e insistía en la misma idea de Cornejo de dar injerencia en la designación a organizaciones intermedias de la sociedad, como las universidades y los Colegios de Abogados ${ }^{13}$. A ello agregaba la inconveniencia de la renovación por tercio, que si bien teóricamente resultaba positiva, para nuestra realidad complicaba el tema de la independencia de los magistrados frente a los poderes del Estado. La necesidad de una ratificación y permanencia en el cargo, traía consigo la pérdida de la independencia.

Por su parte Marcial Rubio y Enrique Bernales, cuestionan la fórmula adoptada por la Constitución de 1979, señalando que "anecdótico puede ser el silencio frente a su independencia, pero es claro que, conformado por tercios elegidos por cada poder, difícilmente podrá enfrentárseles en los casos más arduos de defensa constitucional que, precisamente, son los actos arbitrarios de la autoridad y las normas inconstitucionales» $^{14}$

García Belaunde, no fue del mismo parecer. El consideraba que era inevitable la injerencia de los poderes del Estado en la designación de los magistrados del Tribunal, con excepción del Poder Judicial que consideró no debía intervenir. La filosofía de esta posición la resume de la siguiente manera: "Es que si el Tribunal Constitucional no es elegido por el voto público, para que sea representativo y democrático, entonces debe ser elegido por aquellos que han sido elegidos por el voto político». Agrega el referido jurista peruano que «el $90 \%$ del funcionamiento del Tribunal reposa sobre hábeas corpus y amparos y son esos los denegatorios, no todos, sino solamente los que son denegados, $y$ son denegados ¿por quién?, por la Corte Suprema. En consecuencia,

13 Javier de Belaunde. "En torno al funcionamiento del Tribunal». En El Tribunal de Garantías Constitucionales en debate. p. 129.

14 Marcial Rubio y Enrique. Op. cit., p. 212 
hay una relación directa de causalidad entre lo que decide la Corte y lo que decide el Tribunal, por eso es que creo que por encima de algunos razonamientos teóricos que pueden ser muy refinados, la práctica nos dice que hay una dependencia causal entre ambos, por eso es que yo pienso que el Poder Judicial no debería intervenir en el nombramiento de magistrados del Tribunal ${ }^{15}$.

Nos inclinamos por considerar la conveniencia de la no intervención de ninguno de los poderes del Estado en la designación de los magistrados del Tribunal, en base a lo observado en la actuación, tanto del T.G.C., como del T.C. En efecto, el comportamiento de los magistrados estuvo ligado a los grupos políticos que tuvieron participación en la designación, con honrosas excepciones. Si bien concordamos con García Belaunde en lo que se refiere al poder judicial, no participamos de su parecer respecto de los otros poderes del Estado, porque las causas que resuelve el poder judicial están referidas fundamentalmente a transgresiones por parte del Estado (especialmente del poder ejecutivo).

La Constitución de 1993, diseña la conformación del Tribunal Constitucional con siete miembros (magistrados), todos elegidos por el Congreso de la República, aún cuando es necesario el voto mayoritario que represente dos tercios del número legal de sus miembros, esto es, ochenta votos. La opción del constituyente de 1993, está revestida de legitimidad por cuanto es un órgano elegido democráticamente el que selecciona y designa a los magistrados; sin embargo, el antecedente del T.G.C. nos hace dudar de dicha opción. Abad, señala al respecto: «si bien no estamos en desacuerdo con este modo de designación, tampoco podemos dejar de tomar en cuenta que los sistemas que otorgan una activa participación al Congreso corren el riesgo de politizar -en el sentido partidario del término- la designación de los magistrados. Lo cual es mucho más probable en países con regímenes autoritarios, a los que no les entusiasma el control constitucional ${ }^{16}$

La conformación del Tribunal Constitucional nos demuestra la inconveniencia de la participación del Congreso en la designación de los

15 Domingo García Belaunde, El Tribunal de Garantías Constitucionales en debate. p. 137.

16 Samuel Abad. «La Jurisdicción Constitucional en la Carta Peruana de 1993. Antecedentes, Balance y perspectiva». En Una mirada a los Tribunales Constitucionales. p. 213. 
magistrados. Claramente se ha vislumbrado el afán de ejercer, de alguna manera, un control en el ejercicio de las funciones del Tribunal, tratando de imponer candidatos a como de lugar.

La actuación del Tribunal Constitucional estuvo marcada por la pugna entre los magistrados que pretendieron ejercer las funciones jurídico-políticas con independencia del grupo que hegemonizaba el poder político, con aquellos manifiestamente proclives al gobierno de turno, hasta que ocurrió la defenestración de los primeros, por decisión, a todas luces arbitraria, del Congreso de la República.

Lo que sí es un hecho positivo, dentro del marco de la normatividad, es haber eliminado la renovación por tercios, y el haber fijado un período en el ejercicio de las funciones, sin posibilidad de reelección, lo que elimina aquellas circunstancias que, de alguna manera, puedan perturbar la independencia de los magistrados.

\subsection{Competencia}

Con relación a la competencia del Tribunal Constitucional, han habido variaciones importantes respecto del T.G.C. En efecto, la Constitución de 1979 , Art. $298^{\circ}$, señalaba como competencia del T.G.C. lo siguiente:

1) Declarar a petición de parte, la inconstitucionalidad parcial o total de las leyes, decretos legislativos, normas regionales de carácter general y ordenanzas municipales que contravienen la Constitución por la forma o por el fondo, $y$

2) Conocer en casación las resoluciones denegatorias de la acción de hábeas corpus y la acción de amparo, agotada la vía judicial.

Por su parte, la Constitución de 1993, señala como competencia del Tribunal Constitucional:

1. Conocer, en instancia única, la acción de inconstitucionalidad.

2. Conocer, en última y definitiva instancia, las resoluciones denegatorias de hábeas corpus, amparo, hábeas data, y acción de cumplimiento.

3. Conocer los conflictos de competencia, o de atribuciones asignadas por la Constitución, conforme a ley. 
Dos modificaciones sustanciales: por un lado, se le agrega competencia al Tribunal Constitucional para que conozca los conflictos de competencia o atribuciones, con lo que se determinan las tres funciones básicas de un Tribunal Constitucional (control normativo, tutela de derechos y conflictos de competencia). Algunos autores, como Abad, sostienen que pudo habérsele otorgado otras atribuciones como el control preventivo de los tratados internacionales o el proceso de inconstitucionalidad por omisión. Considera, asimismo, que pudo adoptarse la fórmula española que prevé la concesión de competencias adicionales vía ley ${ }^{17}$.

La otra modificación consiste en que ya no conoce de las acciones de garantía denegatorias, vía casación, luego de agotada la vía judicial. Se convierte el Tribunal Constitucional en última instancia para las acciones de garantía, sea que se inicien ante el Juez Civil o Penal de Primera Instancia o que se inicien en la Corte Superior. En ambos casos, las acciones de garantía sólo tienen dos instancias, de tal suerte que acudirán vía recurso extraordinario ante el Tribunal Constitucional, quien se convierte en tercera y última instancia para los casos en los que se haya denegado la acción de garantía.

Significa ello que las acciones de garantía iniciadas ante el Juez Civil o Penal, serán conocidas en segunda instancia por la Corte Superior, y contra la resolución denegatoria que expida ésta, podrá interponerse el recurso extraordinario para acudir directamente al Tribunal Constitucional, prescindiendo de la Corte Suprema.

En los casos en que la Corte Superior actúa como Primera Instancia, la Corte Suprema actuará como Segunda Instancia, y contra la resolución denegatoria que expida ésta, se podrá acudir vía Recurso Extraordinario ante el Tribunal Constitucional.

Recordemos que, antes de la Constitución de 1993 y de la Ley Orgánica del Tribunal Constitucional, las acciones de garantía culminaban en la Corte Suprema (tres instancias), y vía casación, en los casos que se denegaba la acción de garantía, se acudía al Tribunal de Garantías Constitucionales. Recordemos que en el período comprendido entre el 05 de abril de 1992 hasta la convocatoria a elecciones, el Presidente Fujimori dictó una serie de normas, entre las cuales figura el Decreto Ley $\mathrm{N}^{\circ} 25721$, que otorgaba competencia al desactivado Tribunal de 
Garantías Constitucionales para conocer en casación de las resoluciones de las acciones de amparo en que el Estado es demandado.

Con relación a la acción de inconstitucionalidad, si bien en la carta del 93 no se mencionan las normas contra las cuales se puede interponer demanda de inconstitucionalidad, como sí lo señala la Constitución del 79, la Ley Orgánica del Tribunal Constitucional, Ley $\mathrm{N}^{\circ} 26435$, se encarga de precisar los alcances, en el Art. $20^{\circ}$. En efecto, en el numeral antes mencionado se señala taxativamente que las normas que pueden ser impugnadas de inconstitucionales ante el Tribunal son:
a) Las leyes
b) Los decretos legislativos
c) Los decretos de urgencia
d) Los tratados internacionales
e) Los reglamentos del Congreso
f) Las normas regionales de carácter general, y
g) las ordenanzas municipales

Encontramos una mejora sustancial en cuanto a la competencia del Tribunal Constitucional, al haberse incorporado el conflicto de competencia y atribuciones, que eran temas principales de los Tribunales Constitucionales europeos. De la misma forma, en lo que se refiere a las acciones de garantía, aún cuando desde nuestro punto de vista el Tribunal debería ser competente para estas acciones sólo por la vía de casación, y no convertirse en una tercera instancia. Vía casación sustituiría a la Corte Suprema. La Casación podría regularse considerando sólo los errores in procedendo y los errores in iudicando, como materia de pronunciamiento.

Debe tenerse presente que, en cuanto a las acciones de garantía, la Constitución de 1993 incorpora el hábeas data y la acción de cumplimiento que también son competencia del Tribunal Constitucional como tercera y última instancia, en los mismos términos que la acción de amparo.

\subsection{Legitimación}

La legitimación es la aptitud del sujeto de derecho para intervenir directamente, o por medio de representante, en un proceso determinado, 
como demandante o como demandado. Se tiene legitimación procesal cuando se ejerce por sí mismo sus derechos en un proceso, y ello ocurre cuando se tiene capacidad procesal que coincide, generalmente, con la capacidad de ejercicio que señala la ley civil, o cuando se actúa como apoderado debidamente premunido de representación. Se tiene legitimación ad causam, cuando se forma parte de la relación jurídica que motiva la discrepancia, o cuando se trata de intereses difusos en los que la ley concede legitimidad a determinadas entidades y/o personas.

Hemos comenzado tratando de definir la legitimación, porque fue un tema debatido en la Comisión Principal de la Constitución de la Asamblea Constituyente de 1978-1979, toda vez que la propuesta de su uso la planteó el señor Valle Riestra, optándose por el lenguaje directo que figura en la Constitución de $1979^{18}$.

Tratándose de la acción de inconstitucionalidad, la Constitución de 1979 concedía legitimidad a:

a) El Presidente de la República

b) La Corte Suprema de la República

c) El Fiscal de la Nación

d) Sesenta Diputados

e) Veinte Senadores, y

f) Cincuenta mil ciudadanos con firmas comprobadas por el Jurado Nacional de Elecciones.

Esta disposición fue criticada por cuanto era una relación de autoridades limitada y, por otro lado, era una verdadera traba para los ciudadanos recurrir al Tribunal de Garantías Constitucionales el hecho de tener que reunir cincuenta mil firmas de ciudadanos. El acceso se tornó difícil, poco practicable, cuando en realidad uno de los argumentos en favor del control jurisdiccional concentrado es el fácil acceso.

Por ello es que, desde 1983 hasta 1992, sólo se presentaron quince acciones de inconstitucionalidad ${ }^{19}$.

La Constitución de 1993, amplía el espectro de la legitimidad y, a su vez, disminuye sustancialmente el requisito de firmas para que los

18 Javier Valle Riestra. Diario de Debates de la Comisión Principal de la Asamblea Constituyente de 1978-1979. T.III. pp. 410-411

19 Samuel Abad. Op. cit. p. 194. 
ciudadanos puedan recurrir directamente al Tribunal Constitucional. En efecto, conforme lo señala el Art. $203^{\circ}$ de la Constitución, están facultados para interponer acción de inconstitucionalidad:

a) El Presidente de la República,

b) El Fiscal de la Nación,

c) El Defensor del Pueblo,

d) El 25\% del número legal de congresistas (treinta)

e) Cinco mil ciudadanos, y si se trata de una ordenanza municipal el $1 \%$ de los ciudadanos del respectivo ámbito territorial.

f) Los presidentes de Región y los alcaldes provinciales, en materias de su competencia.

g) Los Colegios Profesionales, en materias de su especialidad.

Como se puede observar, se concede legitimidad a los Presidentes de las regiones y los alcaldes provinciales, en materias de su competencia, así como a los Colegios profesionales, en materias de su especialidad. Encontramos acertada la ampliación, porque las personas jurídicas de Derecho público estatal (Gobiernos regionales y municipalidades provinciales), pueden verse afectadas por disposiciones legales relativas a asuntos de su competencia. De la misma forma, los Colegios Profesionales (personas jurídicas de derecho público no estatal) pueden y deben estar en la capacidad de defender asuntos en las materias que les compete y que sean contrarias a la Constitución. Es una sana apertura para facilitar el acceso al Tribunal Constitucional.

Finalmente, debemos resaltar la importante disminución en el requisito de las firmas que se exigen a los ciudadanos para acudir al Tribunal Constitucional vía acción de inconstitucionalidad de la ley. De cincuenta mil firmas, que antes se exigían, se ha disminuido a sólo cinco mil firmas.

Sin embargo, la Corte Suprema de la República no está legitimada para recurrir al Tribunal Constitucional para que se declare la inconstitucionalidad de una ley o norma equivalente, como sí lo estaba en la Constitución de 1979. No nos parece acertada esta determinación por cuanto se corta la vía incidental que, de alguna manera, estaba presente en Carta de 1979.

Bien sabemos que no ha sido tradición del poder judicial dar cuenta al Congreso de la República de los vacíos o defectos de la legislación, 
conforme lo faculta el Art. X del Título Preliminar del Código Civil de 1984. De la misma forma, no se conoce ninguna demanda planteada por la Corte Suprema ante el Tribunal Constitucional. Sin embargo, ello no es motivo para que se haya eliminado tal facultad a dicho organismo judicial. Era el camino a través del cual los jueces podrían haber planteado la inconstitucionalidad de las leyes, a fin de que lo resuelto por el Tribunal tenga efectos erga omnes.

\subsection{Número de votos que hacen resolución}

Este ha sido uno de los problemas que ha presentado la justicia jurisdiccional en el Perú. Se considera que al señalar seis, como el número de votos necesarios para emitir sentencia en un proceso de inconstitucionalidad, se está provocando la inoperatividad del Tribunal Constitucional, si tenemos en consideración que el número de magistrados es de siete.

La Constitución de 1979, diseñó el TGC con una conformación de nueve miembros, señalando que el quorum era de seis miembros. Las decisiones se tomaban por acuerdo de cinco de sus miembros, pero si se trataba de una acción de inconstitucionalidad, seis votos conformes formaban sentencia. Se requería de las $2 / 3$ partes de los magistrados del Tribunal para que se declare la inconstitucionalidad de una ley. Si bien, no se ajusta a lo que observamos en otros Tribunales, donde se forma sentencia con mayoría simple, sin embargo, no podemos considerar ese número como impracticable. Pero, señalar seis votos conformes de siete, es prácticamente como exigir unanimidad, lo que torna extraordinariamente difícil la declaración de inconstitucionalidad de una ley y, consecuentemente, fácilmente controlable la función principal del Tribunal, por parte del poder político encargado de la designación de los magistrados. Le sería suficiente contar con dos adeptos al régimen para neutralizar la función de control del poder que debe ejercer el Tribunal. Esta realidad la hemos vivido y, por ello, el forcejeo que se produjo al interior del Congreso en el momento que había que elegir a los miembros del Tribunal. En todo caso, la actuación del Tribunal Constitucional no hace sino confirmar lo expresado anteriormente. Sin embargo, se impone una pronta modificación de la Ley Orgánica del Tribunal Constitucional en este aspecto, debiendo adoptarse lo que ya es común en el Derecho Comparado, esto es, decisión por mayoría simple que, en nuestro caso, serían cuatro votos conformes. 
En consecuencia, tal como lo legisla la Ley Orgánica del Tribunal Constitucional, si el quorum es de seis miembros, las decisiones se adoptan por acuerdo de la mayoría simple (cuatro), pero para los asuntos de declaración de inconstitucionalidad de una ley se requiere del voto conforme de seis. Para la primera situación nos estamos refiriendo a las sentencias que emita el Tribunal Constitucional en las acciones de garantía que, como hemos visto, se convierte en tercera instancia, a través del recurso extraordinario que se interpondría, en algunos casos contra las sentencias emitidas por las salas civiles de las Cortes Superiores y, en otros casos, contra las sentencias que emita la Corte Suprema de la República en los asuntos donde interviene como segunda instancia.

\subsection{Sede del Tribunal}

Tanto la Constitución de 1979, como la Constitución de 1993, señalan como sede del Tribunal, la ciudad de Arequipa. Este fue un tema debatido en la Asamblea Constituyente de 1979; se arribó a la solución antes indicada, como consecuencia del planteamiento hecho respecto a la creación de un Congreso económico, idea del Partido Aprista Peruano, que tendría como sede la ciudad de Trujillo, y para compensar al sur del país, y dada la tradición jurídica que ha hecho gala la ciudad de Arequipa, se le sindicó como sede del Tribunal de Garantías Constitucionales. Sin embargo, el Congreso económico no fue aprobado por la Asamblea Constituyente, permaneciendo la idea de que Arequipa sea la sede del TGC.

¿Cuáles han sido las consecuencias de tal designación?. ¿Ha resultado operativo?. La respuesta, a estas alturas, es que más bien ha resultado un obstáculo para el acceso al Tribunal. Si se tiene en consideración que el mayor número de las acciones de garantías constitucionales se inician en la ciudad de Lima, y si la mayor parte de los legitimados para interponer demandas de inconstitucionalidad de las leyes tienen sus domicilios legales en la ciudad de Lima, el gesto de otorgar la sede a la ciudad de Arequipa, no es nada operativo. Creemos que una sana decisión es que Lima sea la sede del Tribunal.

La razón fundamental radica en el hecho de que el TGC no actúa de oficio, sino a instancia de parte; siendo así, el acceso no debe presentar dificultades. 


\subsection{Alcances de la sentencia del Tribunal}

A) Efectos en el tiempo de la sentencia que declara la inconstitucionalidad de una norma.

Tanto la Constitución de 1979 (Art. 300%), como la de 1993 (Art. $204^{\circ}$ ), señalan que la sentencia que declara la inconstitucionalidad de una norma, en todo o en parte, no tiene efectos retroactivos. Significa ello que sus efectos se producen hacia el futuro. Todos los actos jurídicos realizados con anterioridad a la sentencia son válidos. El argumento de la seguridad jurídica fue esgrimido por el constituyente Javier Valle Riestra. Era una forma de evitar el caos que provocaría si al derogarse por inconstitucional una ley se dejara sin efecto todos los actos anteriores verificados mientras estuvo vigente ${ }^{20}$.

Ésta es considerada como una de las diferencias entre el control difuso de la constitucionalidad de las leyes, con el sistema concentrado. En el primero, la sentencia retrotrae sus efectos declarando la nulidad del acto del Estado que es materia del proceso. La sentencia produce efectos en forma retroactiva. En cambio, en el sistema concentrado, sea éste a cargo del Poder Judicial o de un Tribunal Especial, como es el caso nuestro, la sentencia rige los actos hacia el futuro. De esta manera, estamos frente a una situación de anulabilidad, que significa que el acto del Estado «aún irregular o inconstitucional, una vez producido por una institución pública, debe considerarse como un acto del Estado y, como tal, válido y efectivo hasta que el órgano que lo produjo lo derogue o revoque o hasta que se decida su anulación por otro órgano del Estado con los poderes constitucionales correspondientes" ${ }^{21}$.

La garantía que brinda la Constitución es la anulabilidad del acto del Estado considerado inconstitucional. El sistema concentrado tiene la particularidad de que la invalidez o la nulidad del acto legislativo con validez erga ommes ha sido reservado exclusivamente a un solo órgano constitucional que, en nuestro caso, es el Tribunal Constitucional. Los Tribunales ordinarios no tiene facultades para declarar la

20 Javier Valle Riestra. Diario de Debates. T.III. pp. 413-414

21 Allan Brewer-Carias. El Control Concentrado de la Constitucionalidad de las Leyes. p. 19. 
inconstitucionalidad de las leyes, lo que está reservado al Tribunal Especial que puede anular el acto $^{22}$. Esta anulación que la hace el Tribunal Constitucional no tiene efectos retroactivos. Sus efectos son hacia el futuro, y son erga ommes.

B) Derogación de la norma declarada inconstitucional

Entre la Constitución de 1979 y la de 1993 hay una variación importante en lo que se refiere a la derogación de la norma declarada inconstitucional.

La Constitución de 1979 señalaba que el Tribunal comunicaba al Presidente del Congreso, la sentencia que declara la inconstitucionalidad de la norma. El Congreso, por el mérito de dicha sentencia, debía aprobar una ley derogando la norma inconstitucional.

Si transcurrido cuarenticinco días no se promulgaba la ley derogatoria, se entendía que la norma quedaba derogada, debiendo publicarse la sentencia respectiva en el diario oficial.

Podemos afirmar que el efecto inmediato no era la derogatoria de la ley, sino la conminación que se hacía al Congreso para que expida la ley derogatoria correspondiente. El efecto mediato, si era la derogatoria, ya que si el Congreso no lo hacía, se consideraba derogada la ley. Más bien, en los casos de inconstitucionalidad que no sean de leyes, la sentencia se publica en el diario oficial y al día siguiente quedaba sin efecto la norma.

La Constitución de 1993 otorga un solo efecto directo a la sentencia que declara la inconstitucionalidad de una ley o de cualquier otra norma con igual jerarquía. La sentencia se publica en el diario oficial y desde el día siguiente

\section{Perspectivas de la justicia constitucional en el Perú}

No cabe la menor duda de la intrínseca vinculación que existe entre la vigencia de un real sistema de gobierno democrático, y el necesario control del ejercicio del poder, así como el reconocimiento, vigencia y respeto de los derechos fundamentales del ser humano. La vigencia de 
la democracia no es sólo un asunto formal, sino de contenido que se traduce en el respeto a las instituciones básicas de una sociedad y, por otro lado, en el caso peruano, en un proceso de aprendizaje de la cultura democrática que debe partir de las relaciones sociales más primarias, de la vida cotidiana, esto es, de la cultura de la libertad, relaciones igualitarias, tolerancia, diálogo.

Es indudable que el camino no es corto, porque nuestra sociedad presenta características de cultura autoritaria desde sus raíces. Por ello, la responsabilidad de la clase dirigente de promover la cultura democrática y los valores que ella encierra, promoción que indudablemente debe ir acompañada con el ejemplo. La democracia es una forma de vida, con una pléyade de valores que se despliegan en la conducta de los hombres, no una mera declaración, menos una simple formalidad.

Frente a esta realidad, tenemos hoy un sistema de justicia constitucional diseñado, fundamentalmente, en la Constitución de 1993 y en las leyes que regulan las acciones de garantías constitucionales, muchas de ellas reguladas y modificadas durante el período comprendido entre el 05 de abril de 1992, hasta el retorno a la Democracia con la elección del Congreso Constituyente Democrático (fines de 1992), donde claramente se nota el afán de desnaturalizar las acciones de garantía a fin de que pierdan eficacia.

Hemos analizado, en forma comparativa, los dos Tribunales diseñados por las Constituciones de 1979 y 1993, y si bien observamos una serie de modificaciones importantes en lo que se refiere al Tribunal Constitucional, nos quedan tres preocupaciones un tanto desalentadoras, que si bien han sido opciones de los Constituyentes del 93, guardan estrecha relación con aspectos de orden político:

a) El sistema de nombramiento de los magistrados del Tribunal. Los hechos han demostrado que la independencia en el actuar de los magistrados está relacionado con el sistema de nombramiento. El haber determinado que el Congreso sea el encargado de la selección y designación de los magistrados del Tribunal, no soluciona el problema que se reflejó claramente con el Tribunal de Garantías Constitucionales, donde los magistrados con claras tendencias políticas carecían en su mayoría de la independencia necesaria para el ejercicio de sus funciones que implican, fundamentalmente, el control de los actos de los que ejercen el poder. 
b) El número de votos necesarios para formar resolución que declare la inconstitucionalidad de las leyes. De un Tribunal conformado por siete miembros se exigen 06 votos conformes para que se expida resolución. Prácticamente casi unanimidad, que va a resultar una barrera infranqueable para lograr que se produzca una sentencia. Esto favorece al poder que no es proclive al control, y si el poder es el que elige a los miembros del Tribunal, bastaría con dos miembros incondicionales para impedir que se produzca resolución que declare la inconstitucionalidad.

c) La sede del Tribunal. Hemos indicado que la sede del Tribunal creó problemas para el acceso por parte de los ciudadanos, máxime cuando en un porcentaje que alcanza casi el $80 \%$ de los procesos que llegaban al Tribunal provenían de Lima; sin embargo, el número de causas tanto en lo que se refiere a las pretensiones de inconstitucionalidad de leyes, como en las demandas de amparo y hábeas corpus, no guardan relación con el volumen total existente en el Poder Judicial.

Sin embargo, el diseño global es mejor que el propuesto por la Constitución de 1979. En efecto, se mantiene el control mixto de la constitucionalidad, a través del Tribunal Constitucional que conoce, vía acción, las demandas de inconstitucionalidad con efectos erga omnes, con la facultad de derogar la norma inconstitucional con la sola publicación de la sentencia en el diario Oficial y, a través del Poder Judicial el control difuso, aún cuando limitado a la no aplicación de la norma inconstitucional al caso concreto y con efectos exclusivo a dicha causa. En ambos casos, lo que se espera es una conducta independiente de los magistrados que asuman el papel de contralor de la Constitución.

De otro lado, vemos con optimismo que la legitimación procesal para intervenir en los procesos en los que se pretende la declaración de inconstitucionalidad de una norma, se haya extendido a otras instituciones intermedias como los Colegios Profesionales, los presidentes de las Regiones y los Alcaldes Provinciales. Asimismo, que la competencia del Tribunal comprenda ahora los conflictos de competencia o de atribuciones de los organismos del Estado.

En lo que se refiere a las garantías constitucionales, creemos que habría sido más adecuado, establecer un proceso con solo dos instancias en el fuero común y que el Tribunal Constitucional actúe como 
Tribunal de Casación, acompañándose a estas medidas el establecimiento de Salas y Juzgados Constitucionales en las Cortes Superiores respectivas. El establecimiento de tres instancias va en contra de lo que modernamente se aconseja para la administración de justicia, de la que no es ajena la justicia constitucional. Suficiente garantía es la doble instancia, más la posiblidad de acudir a otro órgano, en este caso el Tribunal Constitucional, en casación, donde sólo se revisarán las sentencias en lo que se refiere a los errores in iudicando e in procedendo, esto es, en la correcta aplicación de las normas sustanciales constitucionales y las garantías del debido proceso.

Es preciso señalar que en la Corte Superior del Lima se ha creado una Sala Constitucional, encargada de resolver de todas las sentencias que resuelven los Juzgados en asuntos de acciones de garantías. Esta medida es acertada y debe hacerse extensiva a los demás Distritos Judiciales a fin de propender a la especialización de los magistrados en materia constitucional.

Sin embargo, la regulación de las aciones de garantía, en especial las acciones de hábeas corpus y amparo deben ser revisadas, poniendo atención en los diversos dispositivos, que las desnaturalizaron sustancialmente, así como en lo que se refiere a las medidas cautelares.

Finalmente, de nada valdría todos los esfuerzos doctrinarios, guiados por el afán de mejorar el sistema de la justicia constitucional en el Perú, si no se respeta la Constitución en todas sus dimensiones, a efectos de que las instituciones, como sería el Tribunal Constitucional, despliegue todas sus atribuciones libremente. 